\title{
Creative Thoughts as Acts of Free Will: A Two-Stage Formal Integration
}

\author{
Dean Keith Simonton \\ University of California, Davis
}

\begin{abstract}
This article integrates two topics usually considered disciplines apart, namely, creativity and free will. In particular, creative thoughts are conceived as acts of free will. This integration begins by reviewing recent advances in a specific two-stage theory of creative problem solving, namely blind variation and selective retention (BVSR). After discussing the parallel two-stage theory of free will (chance then choice), both two-stage theories are then integrated into a single formal representation entailing choice initial probabilities, final utilities, and prior knowledge values. These three parameters are used to define the creativity of any given solution and the "sightedness" of any generated thought or choice. Both creativity and free will vanish as sightedness increases, but their relation to blindness is more complex, yielding a triangular joint distribution that mandates a second-stage selection or decision process. In addition, to accommodate the need to create choices actively rather than just decide among given choices, the treatment expands to encompass both thoughts and choices as combinatorial products. This extension connects the discussion of free will with both combinatorial models of creativity and the research on the factors that enable a person to engage in free combinatorial processes. The article closes with suggestions of future empirical and theoretical research with respect to psychology, philosophy, and potential future exchanges between the two disciplines.
\end{abstract}

Keywords: free will, creativity, sightedness, two-stage theories

This article is devoted to integrating two important substantive domains that are normally considered rather far apart, namely, creativity and free will. Indeed, these two topics are most often consigned to separate academic disciplines. Where creativity is primarily a topic addressed by psychologists, free will is far more likely to be discussed by philosophers. For example, handbooks of creativity normally contain chapters written by psychologists (e.g., Kaufman \& Sternberg, 2010), whereas handbooks of free will generally contain chapters written by philosophers (e.g., Kane, 2011b). Moreover, just as psychologists almost never discuss free will in their research on creativity, so do philosophers rarely if ever mention creativity in their analyses of free will. When either psychologists or philosophers venture beyond this implicit substantive and disciplinary demarcation, the resulting discussion with respect to the appended peripheral topic tends to become much more superficial. For instance, libertarian philosophers (i.e., those who argue on behalf of free will) might state that human beings are "creators" of their own lives without drawing any explicit connections with the vast psychological research on creativity (e.g., Kane, 2011c). In fact, such references do not even seem necessary because it quickly becomes clear that every person is deemed a creator in this mundane sense, and thus creativity need not be singled out as a separate and unique phenomenon. The usage is comparable with saying that everyday language practice is creative.

Admittedly, from time to time researchers and scholars will attempt to connect the two substantive domains. For example, an

Correspondence concerning this article should be addressed to Dean Keith Simonton, Department of Psychology, One Shields Avenue, University of California, Davis, CA 95616-8686. E-mail: dksimonton@ucdavis.edu edited volume on free will (Baer, Kaufman, \& Baumeister, 2008) not only includes chapters written mostly by psychologists, but even contains one contribution on creativity (Simonton, 2008). Yet the latter chapter makes very little if any real contact with philosophical and psychological thinking about free will. ${ }^{1}$ On the other side of the coin, a recent edited volume on the philosophy of creativity, though featuring numerous contributions by philosophers, contains no specific treatment of the relation between creativity and free will (Paul \& Kaufman, in press; see also Krausz, Dutton, \& Bardsley, 2009). In short, although discussions of these two issues sometimes overlap, the convergence is shallow rather than profound-and certainly not integrative.

The lack of any meaningful contact might rightfully indicate that the two topics, in reality, have absolutely nothing to do with each other. Yet here I argue for quite the contrary thesis, namely, that the two phenomena may often share a deep underlying mental structure. ${ }^{2}$ This shared cognitive structure is so fundamental that, in particular but significant instances, creativity and free will become identical events. To make this argument, I must show that both creativity and free will often require parallel, even isomorphic two-stage processes, where the initial stage demands the "unin-

\footnotetext{
${ }^{1}$ According to a PsycINFO search conducted just before submitting this paper for publication, this chapter, notwithstanding its abundant deficiencies, remains the only publication in the psychological literature specifically devoted to the relation between creative thought and acts of free will. Though published in 2008, it is also woefully obsolete.

${ }^{2}$ I am very grateful to Bob Doyle, who first brought to my attention the links between the two-stage theory of free will and the BVSR theory of creativity when I gave a colloquium on BVSR at Harvard University in 2009. Nonetheless, he and I have different takes on the specifics of that connection (see Doyle, 2010, 2011, or http://www.informationphilosopher .com, a website providing an extremely comprehensive treatment of the
} 374 
formed" generation of options and the final stage requires the "informed" selection of the best option among those generated.

\section{Integration}

I begin by outlining a formal treatment of a two-stage theory of creativity. That treatment will then provide a conceptual tool for discussing a two-stage theory of free will. Once those two points have been made, the final step is to treat creative thoughts as acts of free will.

\section{Two-Stage Creativity: Blind Variation Then Selective Retention}

More than a half century ago, Campbell (1960) argued that all creativity depends on the two-stage procedure of blind variation and selective retention. This procedure later became abbreviated as "BVSR" (Cziko, 1998; Simonton, 2011b; or BV + SR in Nickles, 2003). Significantly, Campbell believed that BVSR applied not just to creativity but also to "other knowledge processes" (p. 390). Hence, BVSR is also required for the acquisition of all new cognitive understandings and behavioral adaptations (Nickles, 2003). For instance, Skinnerian "operant" conditioning can also be viewed as a BVSR process (Simonton, 1999; see also Dennett, 1995). Regrettably, Campbell failed to provide precise definitions of creativity or blindness, a failure that led to needless debate over the relation between blind variation and creative thought (Simonton, 2011c). Recently, this conceptual failure has been remedied by a proposed set of formal definitions (Simonton, 2013b; cf. Simonton, 2012c). I provide a simplified version of those definitions here, the simplifications designed to emphasize features that carry over most directly to free will (e.g., simultaneous rather than sequential selection; cf. Simonton, 2013a). First creativity will be defined, and then sightedness, the inverse of blindness.

Creativity. Although creativity can adopt many forms, including discovery and exploration, at this point I focus the discussion on creative problem solving (cf. Simonton, 2012b). That is, a person attempts to find a workable solution to an already identified problem. This representation has the special advantage in that many episodes in which volitional behavior takes place are also intrinsically problem solving in nature, such as deciding the optimal course of action from a set of two or more alternatives. Personal choices are often solutions to life's issues (Baumeister, 2008). Given the temporary restriction to creative problem solving, let us now imagine a situation in which a person is trying to solve a central problem. The individual then generates $k$ potential solutions, where $k \geq 1$. Each of these $k$ solutions can be designated by $x_{1}, x_{2}, x_{3} \ldots x_{i} \ldots x_{k}$ and the entire set of solutions by $X$ (cf. Simonton, 2011a). For instance, in Maier's (1931, 1940) classic two-strings problem, participants were asked to tie together the ends of two cords hanging from the ceiling. The participants produced up to seven potential solutions using various provided means, so that $k=7$, of which four solutions actually achieved the specified goal. In short, participants had up to four workable solutions from which to choose their response. The most obvious solution-simply grasping the end of one cord and then tying it to the end of the other-was among the three potential solutions that could not work.
Each potential solution $x_{i}$ in the set $X$ can then be characterized by three distinct psychological parameters that represent subjective probabilities (cf. Simonton, 2011a):

1. The initial probability that the individual will generate solution $x_{i}$ is given by $p_{i}$, where $0 \leq p_{i} \leq 1$. In addition, $\Sigma p_{i} \leq$ 1 , allowing for the possibility that all of the potential solutions to a problem might have probabilities so low that the probabilities will not even sum to unity. This situation arises when all alternative solutions have very weak "response strengths" (e.g., "maybe this or maybe that but maybe none of them" as in exploratory BVSR; Simonton, 2013a). Lastly, if $p_{i}=0$, then the solution $x_{i}$ is not at once accessible, but can presumably be elicited after an incubation period terminated by an appropriate priming stimulus (Hélie \& Ron, 2010; Seifert, Meyer, Davidson, Patalano, \& Yaniv, 1995). If this contingent circumstance is impossible, then $k$ should be reduced to that subset of solutions that can be potentially generated within a reasonable time. The trivial case occurs when $k=0$ because the person cannot conjure up a single relevant solution no matter how long he or she considers the problem. The person then arrives at a permanent impasse. An example would be a perpetual motion machine that generates more energy than it consumes.

2. The final utility, $u_{i}$, is the probability that solution $x_{i}$ will actually prove useful (and hence be selected and retained according to the second half of BVSR). Here $0 \leq u_{i} \leq 1$ (where $0=$ utterly useless and $1=$ maximally useful) and $0 \leq \Sigma u_{i} \leq$ $k$ (i.e., from none of the potential solutions work to all of them work perfectly). Technically, a solution's utility is a continuous variable, yet in many instances, it reduces to a dichotomous $0-1$ attribute. As an example, in Maier's $(1931,1940)$ two-strings problem, a solution either enables the person to tie the two strings together or it wholly fails to do so. Intermediate solutions do not exist. Often set $X$ will contain one solution that works fully whereas all the others fail miserably. The solution is unique.

3. The parameter $v_{i}$ gauges the person's prior knowledge of the utility (where $0 \leq v_{i} \leq 1$ and $0 \leq \Sigma v_{i} \leq k$ ). When $v_{i}=0$, the person is ignorant of whether or not the solution will work without first executing a test, but when $v_{i}=1$ the person knows the value of $u_{i}$ in advance, and perfectly so. In the latter scenario, a generation-and-test, trial-and-error, or variationand-selection procedure is pointless. Thus, in authentic algorithmic problem solving $v_{i}=1$, whereas in heuristic problem solving $v_{i} \ll 1$ (cf. Amabile, 1996; Simonton, 2011b). If the value of $v_{i}$ lies somewhere between 0 and 1 , we may label the solution a mere "hunch" based on tacit knowledge yet to reach consciousness (the precise value representing differing "feeling of knowing" states; cf. Bowers, Regehr, Balthazard, \& Parker, 1990). In this middling range, to discover that the solution proves useful can still trigger surprise. For comprehensiveness, we must also permit the situation where all of the utilities might be perfectly known, whether useful or useless, in which situation $\Sigma v_{i}=k$. When this situation holds, BVSR becomes decidedly superfluous. BVSR is only relevant for separating high utility from low utility solutions when the utilities are initially unknown or imperfectly known. Naturally, any solution with the values $v_{i}=1$ and $u_{i}=0$ will not even be found in set $X$, for then any rational intellect would set $p_{i}=0$, and thus $x_{i}$ will not even be subject to BVSR (cf. the concept of "prese- 
lection" discussed in Simonton, 2011b). For example, theoretical physicists inevitably disregard any hypothesis that would violate one or more unbreakable natural laws, such as the second law of thermodynamics.

Given the above parameters, the creativity of solution $x_{i}$ in set $X$ can be defined as follows (Simonton, 2012a, 2013b; cf. Simonton, 2012c):

$$
c_{i}=\left(1-p_{i}\right) u_{i}\left(1-v_{i}\right), \quad \text { where } \quad 0 \leq c_{i} \leq 1
$$

Here the factor $\left(1-p_{i}\right)$ gives the solution's originality (i.e., highly original solutions have low initial probabilities) and factor $\left(1-v_{i}\right)$ gives the solution's surprisingness, or nonobviousness (i.e., the degree of ignorance before generating and testing the solution to assess its utility). The middle factor $u_{i}$ in Equation 1 is the solution's eventual usefulness or utility, just as before. Expressed in words, the creativity of a given solution is the joint product of its originality, utility, and surprisingness. Although Equation 1 may appear exotic, it actually provides a precise and direct translation of standard three-criterion definitions of creativity, including that imposed by the United States Patent Office to approve applications for protection (Simonton, 2012c; see also Amabile, 1996; Boden, 2004). Because the value of $c_{i}$ ranges from 0 to 1 , it can be interpreted as the probability that the individual will consider $x_{i}$ to be creative.

I must stress that the three parameters are all subjective or personal rather than objective or consensual (cf. Simonton, 2013c). The focus is on an individual attempting to solve a problem to his or her satisfaction without the need to have others accept the solution. Campbell's (1960) original version of BVSR dealt with "thought trials" taking place within a given individual's mind (Simonton, 2011b). In this regard, the creator is like Dennett's (1995) "Popperian creature" who tests conjectures against internal representations of the external world, an internalization of selection that "permits our hypotheses to die in our stead" (p. 375). Notice that the same subjectivity applies to free will. After all, free will also represents a personal rather than consensual event, the individual alone weighing two or more possible courses of action (one of which might even be inaction, as the title character in Shakespeare's Hamlet). On this point both philosophers and psychologists largely concur no matter what their specific take might be on the nature of free will (Baer, Kaufman, \& Baumeister, 2008; Kane, 2011a). Even if an omniscient being is presumed to have advance knowledge of what choice the person will make, the assumption remains that the choice was subjectively experienced as personal assessments of the utilities of various available options (see Hasker, 2011, for comprehensive review).

Sightedness. The most recent reformulations of Campbell's (1960) BVSR have focused the formal representations on "sightedness" rather than "blindness" (Simonton, 2012a, 2012b, 2013a, 2013b). Although sightedness is just the inverse of blindness, the former term has the advantage that it avoids all of the misleading connotations that have accrued to the original concept (cf. Kronfeldner, 2010; Sternberg, 1998). Hence, rather than show that creativity is positively associated with blindness, the goal becomes to demonstrate that creativity is negatively correlated with sightedness-a logically equivalent but emotionally less charged assertion. More exactly, it is useful to define sightedness at two levels, namely, the sightedness of a given potential solution $x_{i}$ and the sightedness of the entire set of potential solutions $X$. Starting with the first assignment, the sightedness of a potential solution $x_{i}$ is defined by the following:

$$
s_{i}=p_{i} u_{i} v_{i}, \quad \text { where } 0 \leq s_{i} \leq 1
$$

On the one hand, a solution is highly sighted $\left(s_{i} \approx 1\right)$ if it is highly probable, highly useful, and highly probable precisely $b e$ cause it is highly useful, that is, the high utility is perfectly known when the solution came at once to mind (cf. Sober, 1992). On the other hand, a solution is highly unsighted $\left(s_{i} \approx 0\right)$ if it has a low probability, a low utility, a low prior knowledge value, or any combination of those three low values. For example, if a solution has a high probability but a low utility or a low probability but a high utility, then it cannot be highly sighted. Unsurprisingly, whenever the prior knowledge parameter approaches zero, then sightedness must equal zero no matter what the values of the first two parameters may be. This provision is critical because it helps us avoid chance agreements between $p_{i}$ and $u_{i}$ that would make mere "lucky guesses" sighted (Simonton, 2013b). For example, if a coin were biased toward heads and a gambler had a similar bias in calling heads, any earnings still must be attributed to pure chance rather than to expertise if the gambler had no knowledge of the coin's bias, whether conscious or unconscious. So, even if $p_{i} u_{i}>0$, whenever $v_{i}=0$ it still holds that $s_{i}=0$.

The sightedness of the entire solution set $X$ can now be defined by using Equation 2 to assess the sightedness of all $k$ potential solutions (Simonton, 2012a, 2013b). Set sightedness is then given by the following:

$$
S=1 / k \sum p_{i} u_{i} v_{i}, \quad \text { where } \quad 0 \leq S \leq 1
$$

Simply put, $S$ is the arithmetic mean of the $k s_{i}$ values, that is, it is the average of the joint products of the initial probabilities, final utilities, and prior knowledge values for all potential solutions. Obviously, $S=0$ whenever $v_{i}=0$ for all $i$ (cf. "total ignorance" in Simonton, 2013a).

Converting the above two measures of sightedness into measures of blindness is straightforward: The blindness of potential solution $x_{i}$ is $b_{i}=1-s_{i}$, whereas the blindness of the entire set $X$ of potential solutions is $B=1-S$. Blindness and sightedness thus represent opposite poles on a blind-sighted continuum (Simonton, 2011a, 2013b). This quantitative contrast is no more mysterious than that between extraversion and introversion as a personality trait.

Now that blindness has been reintroduced into the discussion, I must make it plain that blindness should not be equated with randomness. Although pre-Campbellian versions of BVSR often assumed that ideas were generated solely by chance (Bain, 1855/ 1977; Mach, 1896; Poincaré, 1921), Campbell (1960) made it quite clear that blind variations can emerge from nonrandom, even deterministic processes. He gave the specific example of a radar sweep, a BVSR search procedure that is undeniably systematic but not at all random. Other unambiguous examples are the search grids used in astronomy, archeology, paleontology, and other exploratory disciplines, where Cartesian coordinates substitute for the polar coordinates of radar scans (Simonton, 2011b). 
In more general terms, anytime permutations of an ideational set are generated and tested in a methodical manner, the procedure remains blind to the degree that the probabilities remain "decoupled" from the utilities because the latter are unknown at the outset (Simonton, 2011b; cf. Toulmin, 1972). Most often in these applications, the permutations are equiprobable, without any guidance from the underlying utilities because prior knowledge is absent or nearly so. Yet equiprobability is not a requirement either (Campbell, 1960). For example, computer programs that conduct heuristic searches through a problem space invariably generate and test potential solutions in a manner that is substantially blind (Simonton, 2011b). BACON's rediscovery of Kepler's Third Law provides a fine illustration (Langley, Simon, Bradshaw, \& Zythow, 1987). This discovery program generated and tested alternative polynomial functions, advancing from the simplest to the most complex (albeit skipping redundant tests via the programmed heuristics; Simonton, 2011b). Broadly speaking, generating possible solutions in order of complexity is automatically decoupled from solution utility because the creator cannot predict beforehand the optimal degree of complexity. Occam's razor (the law of parsimony) only advises that we shall not proceed beyond that optimum - which can only be determined after engaging in BVSR procedures that go sufficiently beyond that optimum. This latter necessity often forces backtracking, a common feature of BVSR episodes (Damian \& Simonton, 2011; Simonton, 2007). Once one only goes downhill no matter which direction selected, then the peak has been pinpointed at last.

The bottom line is this: All random variants are blind, but not all blind variants are random. Randomness is just a subset of blindness. Insofar as creativity constitutes an act of free will, the same provision should apply-with signal implications for our understanding of free will.

\section{Two-Stage Free Will: Chance Then Choice}

Given that the question of free will has occupied thinkers for millennia, it should come as no surprise that philosophers have devised a vast number of conceptions of free will (Kane, 2011a). This superfluity of viewpoints also reflects the fact that it is also an especially perplexing issue, particularly when the philosopher attempts to specify how the hypothesized mental event fits with either determinism or indeterminism, both of which are arguably antithetical to free will. Even psychologists - who have been dealing with this issue both more recently and less frequently-can conceive free will in more than one way. For example, Baumeister (2008), a leading psychological researcher in the area, suggests that free will adopts at least two forms, rational choice and selfregulation (or "free won't"). Of these two varieties, BVSR theory is most often closer to rational choice because the "selectionretention" stage typically entails conscious assessment of potential solutions according to utility criteria demanding a cost-benefit calculation. Nonetheless, something more has to be said about where these choices come from if the goal is to scrutinize creative thought as free will. This necessity brings us to the explicit two-stage theory of free will.

In a recent review, Doyle (2010) succinctly expressed a twostage theory of free will as "first chance, then choice" (p. 1). Available choices would be "randomly" produced, but the selection of a particular choice would be decided by the individual's constitution at the very instant that the decision is made (which may sometimes depend on transient moods rather than stable traits). Hence, the "two-stage model effectively separates chance (the indeterministic free element) from choice (an arguably determinate decision that follows causally from one's character, values, and especially feelings and desires at the moment of decision)" (Doyle, 2010, p. 8). Both indeterminism and determinism are reputedly integrated as separate phases in a single two-stage process. Notice that it is not the will that is free, per se, but rather the choices that are free, the person merely willing one choice out of those available at decision time. The term "free will" is in imprecise because the adjective is applied to the wrong noun. The will is determined once the choice is made.

Doyle (2010) argued that the first advocate of this two-stage theory was William James (1884), albeit as a rough prototype. However, this attribution evidently depends on associating James' article on free will with an earlier article on creativity in which an early variety of two-stage theory was proposed (James, 1880; but see Campbell, 1974; Martindale, 2009). Although I do not accept this linkage, there is probably no shortage of thinkers who might be credited with the same idea in some form. ${ }^{3}$ According to Doyle's exhaustive review, numerous other scientists and philosophers have mentioned or discussed the same general model (whether or not they actually advocated the position; see also Doyle, 2011). Besides Doyle himself, an astrophysicist by training and a conspicuous advocate, these investigators are said to include the philosophers Karl Popper, Daniel Dennett, Robert Kane, John Martin Fischer, and Alfred Mele, mathematician and physicist Henri Poincaré, physicist and philosopher Henry Margenau, physicist Arthur Holly Compton, biologist A.O. Gomes, psychologist Stephen Kosslyn, and neurogeneticist Martin Heisenberg, the son of the physicist Werner Heisenberg, the discoverer of quantum indeterminancy (see also Doyle, 2009).

Of those just cited, Popper, Dennett, and Poincaré are equally notable for also discussing an implicit version of a BVSR theory (Dennett, 1995; Poincaré, 1921; Popper, 1963), whether with respect to epistemology in general or creativity in particular (cf. Doyle, 2011). Thus, Dennett (1978) compared the two-stage model to the unambiguously BVSR description of the creative process previously advanced by the French poet, Paul Valéry: "It takes two to invent anything. The one makes up combinations; the other one chooses, recognizes what is important to him in the mass of things which the former has imparted to him" (Hadamard, 1945, p. 30; see also Simonton, 1988, p. 38). Valéry's expression has the special advantage that it does not require that the combinations be generated by chance, but only that the first stage be independent of the second stage. Chance constitutes only one means to ensure independence between the combination generator and the combi-

\footnotetext{
${ }^{3}$ Tellingly, James' (1884) concrete example of an act of free will- his choice of either Divinity Avenue (D) or Oxford Street (O) to get home from his talk at Divinity Hall-does not even illustrate the two-stage theory. Rather than "first chance, then choice," the episode can be better specified as "first options, then random choice" (cf. Doyle, 2010). The "chance" component is located in the wrong stage. Interestingly, if we really can assume that the two paths home are equivalent in James' mind, then we obtain $p_{\mathrm{D}}=.5$ and $p_{\mathrm{O}}=.5, u_{\mathrm{D}}=1$ and $u_{\mathrm{O}}=1$, and $v_{\mathrm{D}}=1$ and $v_{\mathrm{O}}=1$, yielding $c_{\mathrm{D}}=c_{\mathrm{O}}=0$, so the decision was not even creative.
} 
nation selector. The independence or decoupling is the most critical feature, for without it the "chooser" or "selector" is reduced to a "rubber stamper" so that no genuine choice or selection is actually made (cf. Kronfeldner, 2010).

To appreciate this last point more fully, we can use Equations 2 and 3 to recast what must happen in the first stage. Now we have a set $X$ consisting of the $k$ choices $x_{1}, x_{2}, x_{3} \ldots x_{i} \ldots x_{k}$. The sightedness of a given choice is given by Equation 2 and the sightedness of the whole set is given by Equation 3. The parameters are defined approximately as before, with only slight adjustments: $p_{i}$ is still the initial probability (or response strength) of the choice and $v_{i}$ remains the prior knowledge of the choice's utility (or probability of selection and application), but the final utility $u_{i}$ can now represent something broader and perhaps more ephemeral, namely the extent to which choice $x_{i}$ complies with the person's "character, values, ... feelings and desires at the moment of decision" (Doyle, 2010, p. 8). If a particular choice is generated in complete ignorance of this utility value, then $s_{i}=0$, and thus the choice is unsighted without necessarily being random. Similarly, if the entire set of choices is conceived without prior knowledge of the actual utilities, then $S=0$, and again the choices are all "blind" even if none of the options was generated by chance.

What can it mean for choices to be produced blindly but not randomly? What was said with respect to BVSR creativity applies equally well to two-stage free will: As long as the options are first generated without foreknowledge of their subjective utilities, then the choices remain unsighted. Systematic search through a set of alternative possibilities thus can count as blind but nonrandom. The result is a volitional analog of the radar sweep or search grid.

As an example, consider a high school senior trying to decide what she should put down for a prospective major on her college application. The student initially has no knowledge whatsoever about what her options are, and thus visits the college's webpage to find an alphabetical list of available majors (e.g., http:// admissions.ucdavis.edu/majors/). The applicant, being extremely conscientious, then proceeds down the list from A to Z (where $k>$ 100), clicking on the links one by one, checking the course requirements and career options, and then assigns an approximate utility value to each choice (almost all, including both Psychology and Philosophy, getting an absolute zero, and hence $S \approx 0$ ). By the time the applicant has advanced from "Aerospace Science \& Engineering" to "Women's Studies," she might be able to decide which major appears most compatible with her given collection of abilities, interests, and values. Even so, just as a solution search ordered by complexity is systematic but blind, so is a search governed by alphabetical order. Yet neither search procedure involves chance or randomness in any way whatsoever. That said, the applicant might "chance upon" a highly attractive major that she would have ever have possibly conceived on her own, such as "Ecological Management \& Restoration." Given that both $v_{i}$ and $p_{i}$ must be very small (viz., $v_{i} \approx 0$ and $p_{i}<1 / 100$ for all $i$ ), then according to Equation 1 this choice must rate very high in personal creativity as well (viz., $c_{1} \approx 1$ where $x_{1}=$ "Ecological Management \& Restoration"). Her solution to this life problem is original, useful, and surprising. In fact, she's so excited that she can't wait to tell her parents and friends.

Of course, the college applicant might have been much more sighted in the choice of major. Ever since childhood, the person might have loved to act in plays, had persistent dreams of appearing in a principal role in a Broadway production, and can only imagine a single major that would facilitate the achievement of those aspirations. Under these conditions, $p_{1}=1, u_{1}=1$, and $v_{1}=$ 1 , and thus $s_{1}=S=1$, where $x_{1}=$ "Dramatic Art." There is no bona fide free choice but rather a fixed foreclosure on options, and he puts down a major on his application that his parents and friends would have predicted from the time he was in elementary school. The only reason to look over the list of majors is to confirm that the university actually had the desired major. Despite the subject of the major itself, which seems highly creative, the personal choice itself would not be creative at all. The proper decision is obvious from the get-go, rendering $k=1$. This scenario exemplifies routine thinking where the so-called "choice" is a foregone conclusion.

To reiterate, the key to two-stage free will is not whether the choices are randomly generated, but rather whether the choices are generated without prior knowledge of their utility-the odds that they will actually be chosen after rational consideration. The sightedness measures $S$ and $s_{i}$ represent the magnitude of the individual's predecision ignorance regarding, respectively, the set $X$ of choices and the particular choice $x_{i}$. Hence, the inverse measure $B$ can be considered a direct quantitative gauge of the degree to which the set of choices are in fact free of prior subjective determination. The same implication holds for $b_{i}$ with regard to a specific choice. As blindness approaches unity, the set of choices or a specific choice becomes less predictable and hence more free. The student who decided to major in Ecological Management \& Restoration has surprised herself much more than the student who decided to major in Dramatic Art.

The point of the above examples is to illustrate how choices can be systematically generated and still be blind insofar as the person does not know in advance which options will actually prove most useful.

\section{Two-Stage Creativity and Free Will}

To link creative thought with acts of free will requires two final elaborations. First, I must discuss the central circumstances that enhance creativity, circumstances that should support free will as well. Second, it is necessary to say something about how creative thoughts emerge in the first place, particularly if they are to be considered genuine acts of free will.

Creative solutions, blindness, and freedom of choice. In finding a suitable academic major, the emphasis is on utility, not creativity. A creative individual, in contrast, is engaged in finding the most original, useful, and surprising solution to a given problem. Indeed, under certain conditions, an act of creativity can willfully sacrifice utility for originality or surprisingness (Simonton, 2012c). The possibility of tradeoffs is implied by Equation 1 where, so long as $c_{i}<1$, the factors $\left(1-p_{i}\right), u_{i}$, and $\left(1-v_{i}\right)$ may assume a variety of values and still obtain the same threefold joint product. The pliers as pendulum solution to the two-strings problem can be considered an example of giving up a little utility for the sake of higher creativity (Maier, 1940). The pendulum solution was more inconvenient than the other three solutions because it 
alone required that the string first be shortened, whereas all other solutions could use the string unaltered. ${ }^{4}$

Now if the person's goal is to generate creative solutions to problems, then it becomes imperative to determine the conditions that increase creativity. Let us start with the relation between creativity and sightedness. Comparison of Equation 1 with Equations 2 and 3 suggests that creativity and sightedness should be negatively correlated. In particular, although $u_{i}$ plays the same positive role in all three equations (i.e., both creative and sighted solutions must be useful), the initial probability $p_{i}$ is inversely related to originality $\left(1-p_{i}\right)$ and the prior knowledge value $v_{i}$ is inversely related to surprisingness $\left(1-v_{i}\right)$. Nevertheless, the precise relation is far more subtle (Simonton, 2013b).

On the one hand, as the sightedness of a given solution $x_{i}$ increases, its creativity must tend to decrease (i.e., as $s_{i} \rightarrow 1, c_{i} \rightarrow$ 0 for any $i$ ). Similarly, as the sightedness of set $X$ increases, the creativity of the solutions contained in that set will tend to decrease (i.e., as $S \rightarrow 1, c_{i} \rightarrow 0$ for all $i$ ). Whatever the utility value, highly probable and highly obvious solutions cannot be creative.

On the other hand, matters get more complex when we turn the comparison around to ask what happens when blindness is increased (Simonton, 2012a, 2013b). In general, as $b_{i} \rightarrow 1$, (a) the expected value $\left(M_{c}\right)$ of $c_{i}$ will increase, (b) the variance of $c_{i}\left(\sigma_{c}^{2}\right)$ will increase, and (c) the maximum possible creativity (or $c$-max) will increase. Yet the distribution of $c_{i}$ will also become highly skewed, most solutions being very low in creativity. Taken together, the result is a distinctive triangular distribution indicating that blindness is a necessary but not sufficient condition for creativity.

To illustrate, Figure 1 presents a scatter plot generated by a Monte Carlo simulation of the creativity-sightedness relationship (Simonton, 2012a). The distribution makes it clear why BVSR is required in creative thought. Although the most creative solutions are located in the blind end of the distribution, these solutions are mixed with many more far less creative solutions. Hence, the scarce grains of wheat must be winnowed from the abundant chaff. Rendering the selection process all the more arduous but urgent, the bigger the grains, the more voluminous the chaff.

By now, it should also become evident why creative thoughts can be counted as acts of free will as defined by the two-stage conception. Such thoughts satisfy the requirement that they be emitted in ignorance of whether or not they will actually be chosen. Because solution generation is at least partially independent from solution selection, the final choice is not a foregone conclusion. Furthermore, the more creative the idea, the greater is the magnitude of freedom because sightedness must be minimized to attain a higher level of creativity. This consequence is critical because it emphasizes that free will must be a quantitative rather than qualitative phenomenon. It is not a matter of whether or not one has free will but the degree of freedom displayed in the set of choices.

Once the quantitative nature of free will is acknowledged, then the obvious next question is what factors serve to increase or decrease the magnitude of free will. These critical factors will obviously be those that increase $B$ for the set of choices and $b_{i}$ for the particular choice $x_{i}$ in that set. Because these influences have already been worked out in recent versions of the BVSR theory of creativity, it is easy to specify what the relevant factors are

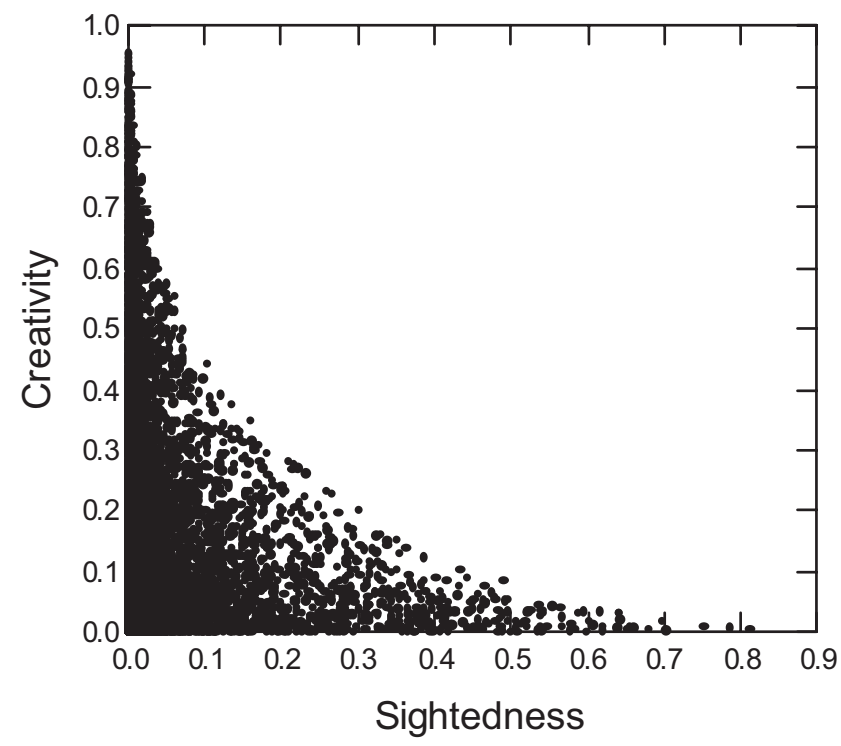

Figure 1. Monte Carlo simulated scatter plot showing the relation between sightedness and creativity for prospective solutions, where creativity is defined according to Equation 1 and sightedness according to Equation 2 and where $p_{i}, u_{i}$, and $v_{i}$ have a uniform distributions. The figure is adapted from Figure 4 in "Combinatorial creativity and sightedness: Monte Carlo simulations using three-criterion definitions," by D. K. Simonton, 2012, The International Journal of Creativity \& Problem Solving, 22, pp. 5-17.

(Simonton, 2013b). Just the two most critical need be mentioned here, both operating mutatis mutandis.

First, free will tends to increase as $k$ increases, that is, the more choices (or "alternative possibilities") contained in $X$, the less sighted any single choice in that set tends to be. A student who selects from prospective 100 majors has more freedom than one who "selects" from only one.

Second, as the generation probabilities become more equiprobable (e.g., as $p_{i} \rightarrow 1 / k$ for all $i$ ), then free will tend to increase as well (i.e., the alternative possibilities should be comparable). The student who views many majors as having the same "cost-benefit ratio" (e.g., demanding course work vs. later career opportunities) will have more freedom than one who sees just one major as vastly superior to the rest.

In brief, the greater the number of choices available and/or the more equivalent the available choices, the more free will is active in the set of those choices and in any given choice within that set. By extrapolation, these implications then tell us that the college applicant who chose to major in Ecological Management \& Res-

\footnotetext{
${ }^{4}$ This point is often overlooked in introductory textbooks where the two strings are usually depicted as too short to reach the floor (e.g., M. W. Eysenck, 2004, p. 337). This misrepresentation makes the pendulum solution much more obvious than it was to the participants engaged in the laboratory experiment. The string unaltered would not swing even with a pliers tied to its end.
} 
toration experienced more freedom than the one who decided on Dramatic Art.

Creative ideas and volitional choices as combinatorial products. It might be easily objected that the examples just used to illustrate free will are too constraining. After all, selecting a college major involves choosing from a predetermined list of options. It is analogous to a person accused of a crime having to decide between (a) accepting a plea bargain for a conviction on manslaughter and (b) going for acquittal in a jury trial on the charge of first-degree murder. The individual would rather have faced different choices. The highest level of personal freedom must entail the ability to generate novel options spontaneously. Even when some options are already given by the circumstances, and thus beyond the person's control, more attractive alternatives can be produced that permit escape from an unfortunate situation. The student might decide to enter culinary school instead of college or the crime suspect might decide to jump bail, flee the country, and seek political asylum. In short, the person must have the capacity to create his or her choices.

To accommodate this requirement most effectively, it is necessary to broaden our concept of creativity. Up to this point, creative thought has been treated in terms of problem solving. Nonetheless, because not all creative acts entail problem solving, it is necessary to find a more general conception that includes creative solutions as a special case. It is often argued that all forms of creativity can be best viewed as combinatorial products (e.g., Mednick, 1962; Poincaré, 1921; Simonton, 1988, 2010; Thagard, 2012). For instance, the potential solutions to Maier's $(1931,1940)$ two-strings problem all involved some combination of one string with some other object in the laboratory-a chair, extension cord, pole, or pliers-plus the addition of some operations, such as attaching the string to the object and then using that object to hold, pull, or swing the string. Some combinations proved useful and some not. For example, participants who tried to use the pliers as tongs to pull one string over to the other discovered that the combination remained too short to work. Viewing creative thoughts as combinatorial products has two main assets.

First, such a conception permits creativity to be analyzed using combinatorial models both mathematical and computational (e.g., Simonton, 2010; Thagard \& Stewart, 2011). These models have achieved substantial successes in explicating the key features of the phenomenon (see, e.g., Simonton, 1997). Therefore, the spontaneous generation of choices might also be conceived as a combinatorial process (see also Dennett, 1978). This combinatorial process constitutes the first step of what has been called "Valerian free will," after the Valéry quote presented earlier in this article (Doyle, 2011). Even more importantly, these combinatorial models often use pseudorandom number generators to simulate creative phenomena, suggesting that creative processes act as if they are driven by chance whatever might be the hypothetical deterministic underpinnings (Simonton, 2003, 2010, 2012a). The same may apply to the first stage of free will.

Second, combinatorial models have been linked with empirical research on the cognitive processes, personal traits, developmental experiences, and environmental contexts associated with creative thought (Simonton \& Damian, 2013; Simonton, 2003, 2010). Examples include divergent thinking and remote or rare associations (Carson, Peterson, \& Higgins, 2005; Gough, 1976; Guilford, 1967; Mednick, 1962), reduced latent inhibition, defocused atten- tion, or cognitive disinhibition (Carson, Peterson, \& Higgins, 2003; Kéri, 2011; Mendelsohn, 1976), openness to experience (Carson, Peterson, \& Higgins, 2005; Harris, 2004; King, Walker, \& Broyles, 1996; McCrae, 1987), psychoticism (H. J. Eysenck, 1994; Stavridou \& Furnham, 1996; cf. Acar \& Runco, 2012), multicultural experiences (Leung \& Chiu, 2008; Leung, Maddux, Galinsky, \& Chiu, 2008; Maddux, Adam, \& Galinsky, 2010; Saad, Damian, Benet-Martinez, Moons, \& Robins, in press), and various forms of novel, random, incongruous, or chaotic environmental stimuli (Proctor, 1993; Ritter et al., 2012; Rothenberg, 1986; Vohs, Redden, \& Rahinel, in press; Wan \& Chiu, 2002). These factors separately and together enable the person to "think outside the box" and thereby conceive combinations located on the left side of the scatter plot shown in Figure 1, including those relatively infrequent combinations that are original, useful, and surprising. Of course, to the extent that free will requires creative thought to set up the set of choices, these same variables can be said to facilitate personal freedom.

\section{Discussion}

I have argued that creative thoughts represent acts of free will. This argument was based on the realization that the BVSR theory of creativity and the chance-then-choice theory of free will can be given the same underlying psychological structure (cf. Doyle, 2011). In either case, ideas are first blindly generated, and then the most useful of those ideas are selected. In support of this contention, I showed how the recent formal specification of BVSR creativity could be extended with minimal modification to twostage free will. This extension had two important aspects. First, because a continuous measure of "sightedness" gauges the extent to which choices are psychologically determined, free will becomes a quantitative rather than dichotomous event. That is, such acts can vary in the degree of freedom exhibited-just as holds for the creativity of thoughts. Second, although blindness is guaranteed by randomness, ideas can be blind without assuming randomness. The sufficient requirement for blindness is that the ideas are generated without complete prior knowledge of their utilities, thus setting up the need for a second stage of selection or choice. Highly sighted ideas can be neither creative nor free.

I hasten to reiterate that not all acts of free will constitute acts of creativity. On the contrary, creative thoughts only form a small subset of all possible free acts under the two-stage concept. Many if not most free choices will not be creative, like deciding which dinner special to order at a restaurant. Even so, it is impossible for an act of creativity not to be free. Better yet, the greater the creativity, the greater the degree of freedom, at least on the average. This statement follows directly from the assumption that both phenomena are contingent on the degree of blindness in the initial generation of the thought or choice.

Because this formal integration involves two topics most frequently investigated by researchers in separate disciplines-creativity in psychology and free will in philosophy - it is reasonable to ask how psychologists and philosophers might best respond to this integrative effort. Given the different research strategies in the two disciplines, the most likely responses diverge. On the one hand, psychologists will most likely want to work out the empirical implications of the theoretical presentation (cf. Baer, Kaufman, \& Baumeister, 2008). For instance, what is the actual relation be- 
tween creativity and free will in terms of their hypothesized psychological correlates? Is reduced latent inhibition or enhanced multiculturalism associated with greater personal autonomy as well as creativity? On the other hand, philosophers will be more prone to engage in logical analyses in line with the standard positions on the age-old intellectual controversy (cf. Kane, 2011b). For example, how exactly does the crucial blind-sighted dimension fit with the three main classic stances, namely, determinism, libertarianism, and compatibilism? Did substituting blindness for "chance" from "first chance, then choice" provide a unique solution or just constitute a conceptual legerdemain? Can freedom really be a matter of degree?

Fortunately, not only are increasingly more psychologists interested in the problem of free will (Baer, Kaufman, \& Baumeister, 2008), but also a growing number of philosophers are fascinated with creativity (Krausz, Dutton, \& Bardsley, 2009; Paul \& Kaufman, in press). In addition, some philosophers have become open to potential psychological contributions to comprehending free will (Mele, 2008; Nichols, 2008). Ideally, psychologists should display the same openness to philosophical work on the subject. As William James (1892/1952) himself noted in his Principles of Psychology, "My own belief is that the question of free-will is insoluble on strictly psychologic grounds" (p. 822). Hence, it is conceivable that issues raised here might be most fully resolved by the joint contributions of researchers in both disciplines. That optimistic forecast has a precedent: Campbell's (1960) BVSR theory of creative thought was subjected to several decades of inquiry by both psychologists and philosophers, inquiries that led to some genuine intellectual progress (e.g., Kronfeldner, 2010; Nickles, 2003; Simonton, 2011b). A comparable interdisciplinary exchange may have similar benefits with respect to understanding the connection between creativity and free will.

\section{References}

Acar, S., \& Runco, M. A. (2012). Psychoticism and creativity: A metaanalytic review. Psychology of Aesthetics, Creativity, and the Arts, 6, 341-350. doi:10.1037/a0027497

Amabile, T. M. (1996). Creativity in context: Update to the social psychology of creativity. Boulder, CO: Westview.

Baer, J., Kaufman, J. C., \& Baumeister, R. F. (Eds.). (2008). Are we free? Psychology and free will. New York, NY: Oxford University Press. doi:10.1093/acprof:oso/9780195189636.001.0001

Bain, A. (1977). The senses and the intellect. Washington, DC: University Publications of America. (Original work published 1855).

Baumeister, R. F. (2008). Free will, consciousness, and cultural animals. In J. Baer, J. C. Kaufman, \& R. F. Baumeister (Eds.), Are we free? Psychology and free will (pp. 65-85). New York, NY: Oxford University Press. doi:10.1093/acprof:oso/9780195189636.003.0005

Boden, M. A. (2004). The creative mind: Myths \& mechanisms (2nd ed.). New York, NY: Routledge.

Bowers, K. S., Regehr, G., Balthazard, C., \& Parker, K. (1990). Intuition in the context of discovery. Cognitive Psychology, 22, 72-110. doi: 10.1016/0010-0285(90)90004-N

Campbell, D. T. (1960). Blind variation and selective retention in creative thought as in other knowledge processes. Psychological Review, 67, 380-400. doi: $10.1037 / \mathrm{h} 0040373$

Campbell, D. T. (1974). Evolutionary epistemology. In P. A. Schlipp (Ed.), The philosophy of Karl Popper (pp. 413-463). La Salle, IL: Open Court.

Carson, S. H., Peterson, J. B., \& Higgins, D. M. (2003). Decreased latent inhibition is associated with increased creative achievement in high- functioning individuals. Journal of Personality and Social Psychology, 85, 499-506. doi:10.1037/0022-3514.85.3.499

Carson, S. H., Peterson, J. B., \& Higgins, D. M. (2005). Reliability, validity, and factor structure of the Creative Achievement Questionnaire. Creativity Research Journal, 17, 37-50. doi:10.1207/s15326934crj1701_4

Cziko, G. A. (1998). From blind to creative: In defense of Donald Campbell's selectionist theory of human creativity. The Journal of Creative Behavior, 32, 192-209. doi:10.1002/j.2162-6057.1998.tb00815.x

Damian, R. I., \& Simonton, D. K. (2011). From past to future art: The creative impact of Picasso's 1935 Minotauromachy on his 1937 Guernica. Psychology of Aesthetics, Creativity, and the Arts, 5, 360-369. doi:10.1037/a0023017

Dennett, D. C. (1978). Brainstorms: Philosophical essays on mind and psychology. Hassocks, UK: Harvester Press.

Dennett, D. C. (1995). Darwin's dangerous idea: Evolution and the meanings of life. New York, NY: Simon \& Schuster.

Doyle, R. O. (2009, June 25). Free will: It's a normal biological property, not a gift or a mystery. Nature, 459, 1052. doi:10.1038/4591052c

Doyle, B. (2010). Jamesian free will, the two-stage model of William James. William James Studies, 5, 1-28. Retrieved December 31, 2010, from http://williamjamesstudies.org/5.1/doyle.pdf

Doyle, B. (2011). Free will: The scandal in philosophy. Cambridge, MA: I-Phi Press. Retrieved November 5, 2012, from http://informationphilosopher .com/books/Free_Will_Scandal.pdf

Eysenck, H. J. (1994). Creativity and personality: Word association, origence, and Psychoticism. Creativity Research Journal, 7, 209-216. doi:10.1080/10400419409534525

Eysenck, M. W. (2004). Psychology: An international perspective. New York, NY: Psychology Press.

Gough, H. G. (1976). Studying creativity by means of word association tests. Journal of Applied Psychology, 61, 348-353. doi:10.1037/00219010.61.3.348

Guilford, J. P. (1967). The nature of human intelligence. New York, NY: McGraw-Hill.

Hadamard, J. (1945). The psychology of invention in the mathematical field. Princeton, NJ: Princeton University Press.

Harris, J. A. (2004). Measured intelligence, achievement, openness to experience, and creativity. Personality and Individual Differences, 36, 913-929. doi:10.1016/S0191-8869(03)00161-2

Hasker, W. (2011). Divine knowledge and human freedom. In R. Kane (Ed.), The Oxford handbook of free will (2nd ed., pp. 39-54). New York, NY: Oxford University Press. doi:10.1093/oxfordhb/9780195399691 .003 .0002

Hélie, S., \& Ron, S. (2010). Incubation, insight, and creative problem solving: A unified theory and a connectionist model. Psychological Review, 117, 994-1024. doi:10.1037/a0019532

James, W. (1880, October). Great men, great thoughts, and the environment. Atlantic Monthly, 46, 441-459.

James, W. (1884). The dilemma of determinism. Unitarian Review and Religious Magazine, 22, 193-224.

James, W. (1952). The principles of psychology. In R. M. Hutchins (Ed.), Great books of the Western world (Vol. 53). Chicago, IL: Encyclopaedia Britannica. (Original work published 1892).

Kane, R. (2011a). Introduction: The contours of contemporary free-will debates (Pt. 2). In R. Kane (Ed.), The Oxford handbook of free will (2nd ed., pp. 3-35). New York, NY: Oxford University Press. doi:10.1093/ oxfordhb/9780195399691.003.0001

Kane, R. (Ed.), (2011b). The Oxford handbook of free will (2nd ed.). New York, NY: Oxford University Press. doi:10.1093/oxfordhb/ 9780195399691.001.0001

Kane, R. (2011c). Rethinking free will: A new perspective on an ancient problem. In R. Kane (Ed.), The Oxford handbook of free will (2nd ed., pp. 381-404). New York, NY: Oxford University Press. doi:10.1093/ oxfordhb/9780195399691.003.0019 
Kaufman, J. C., \& Sternberg, R. J. (Eds.). (2010). Cambridge handbook of creativity. New York, NY: Cambridge University Press. doi:10.1017/ CBO9780511763205

Kéri, S. (2011). Solitary minds and social capital: Latent inhibition, general intellectual functions and social network size predict creative achievements. Psychology of Aesthetics, Creativity, and the Arts, 5, 215-221. doi: $10.1037 / \mathrm{a} 0022000$

King, L. A., Walker, L. M., \& Broyles, S. J. (1996). Creativity and the five factor model. Journal of Research in Personality, 30, 189-203. doi: 10.1006/jrpe.1996.0013

Krausz, M., Dutton, D., \& Bardsley, K. (Eds.). (2009). The idea of creativity (2nd ed.). Leiden, The Netherlands: Brill.

Kronfeldner, M. E. (2010). Darwinian "blind" hypothesis formation revisited. Synthese, 175, 193-218. doi:10.1007/s11229-009-9498-8

Langley, P., Simon, H. A., Bradshaw, G. L., \& Zythow, J. M. (1987). Scientific discovery. Cambridge, MA: MIT Press.

Leung, A. K., \& Chiu, C. (2008). Interactive effects of multicultural experiences and openness to experience on creative potential. Creativity Research Journal, 20, 376-382. doi:10.1080/10400410802391371

Leung, A. K., Maddux, W. W., Galinsky, A. D., \& Chiu, C. (2008). Multicultural experience enhances creativity: The when and how. American Psychologist, 63, 169-181. doi:10.1037/0003-066X.63.3.169

Mach, E. (1896, January). On the part played by accident in invention and discovery. Monist, 6, 161-175. doi:10.5840/monist18966215

Maddux, W. W., Adam, H., \& Galinsky, A. D. (2010). When in Rome ... learn why the Romans do what they do: How multicultural learning experiences facilitate creativity. Personality and Social Psychology Bulletin, 36, 731-741. doi:10.1177/0146167210367786

Maier, N. R. F. (1931). Reasoning in humans: II. The solution of a problem and its appearance in consciousness. Journal of Comparative Psychology, 12, 181-194. doi:10.1037/h0071361

Maier, N. R. F. (1940). The behavioral mechanisms concerned with problem solving. Psychological Review, 47, 43-58. doi:10.1037/h0058466

Martindale, C. (2009). Evolutionary models of innovation and creativity. In T. Rickards, M. Runco, \& S. Moger (Eds.), Routledge companion to creativity (pp. 109-118). London, UK: Taylor \& Francis.

McCrae, R. R. (1987). Creativity, divergent thinking, and openness to experience. Journal of Personality and Social Psychology, 52, 12581265. doi:10.1037/0022-3514.52.6.1258

Mednick, S. A. (1962). The associative basis of the creative process. Psychological Review, 69, 220-232. doi:10.1037/h0048850

Mele, A. R. (2008). Psychology and free will: A commentary. In J. Baer, J. C. Kaufman, \& R. F. Baumeister (Eds.), Are we free? Psychology and free will (pp. 325-346). New York, NY: Oxford University Press. doi:10.1093/acprof:oso/9780195189636.003.0018

Mendelsohn, G. A. (1976). Associative and attentional processes in creative performance. Journal of Personality, 44, 341-369. doi:10.1111/j 1467-6494.1976.tb00127.x

Nichols, S. (2008). How can psychology contribute to the free will debate? In J. Baer, J. C. Kaufman, \& R. F. Baumeister (Eds.), Are we free? Psychology and free will (pp. 10-31). New York, NY: Oxford University Press. doi:10.1093/acprof:oso/9780195189636.003.0002

Nickles, T. (2003). Evolutionary models of innovation and the Meno problem. In L. V. Shavinina (Ed.), The international handbook on innovation (pp. 54-78). New York, NY: Elsevier Science. doi:10.1016/ B978-008044198-6/50006-1

Paul, E. S., \& Kaufman, S. B. (Eds.). (in press). Philosophy of creativity. New York, NY: Oxford University Press.

Poincaré, H. (1921). The foundations of science: Science and hypothesis, the value of science, science and method (G. B. Halstead, Trans.). New York, NY: Science Press.

Popper, K. (1963). Conjectures and refutations. London, UK: Routledge. Proctor, R. A. (1993). Computer stimulated associations. Creativity Research Journal, 6, 391-400. doi:10.1080/10400419309534494
Ritter, S. M., Damian, R. I., Simonton, D. K., van Baaren, R. B., Strick, M., Derks, J., \& Dijksterhuis, A. (2012). Diversifying experiences enhance cognitive flexibility. Journal of Experimental Social Psychology, 48, 961-964. doi:10.1016/j.jesp.2012.02.009

Rothenberg, A. (1986). Artistic creation as stimulated by superimposed versus combined-composite visual images. Journal of Personality and Social Psychology, 50, 370-381. doi:10.1037/0022-3514.50.2.370

Saad, C. S., Damian, R. I., Benet-Martinez, V., Moons, W. G., \& Robins, R. W. (in press). Multiculturalism and creativity: Effects of cultural context, bicultural identity, and cognitive fluency. Social Psychological and Personality Science. doi:10.1177/1948550612456560

Seifert, C. M., Meyer, D. E., Davidson, N., Patalano, A. L., \& Yaniv, I. (1995). Demystification of cognitive insight: Opportunistic assimilation and the prepared-mind perspective. In R. J. Sternberg \& J. E. Davidson (Eds.), The nature of insight (pp. 65-124). Cambridge, MA: MIT Press.

Simonton, D. K. (1988). Scientific genius: A psychology of science. Cambridge, UK: Cambridge University Press.

Simonton, D. K. (1997). Creative productivity: A predictive and explanatory model of career trajectories and landmarks. Psychological Review, 104, 66-89. doi:10.1037/0033-295X.104.1.66

Simonton, D. K. (1999). Origins of genius: Darwinian perspectives on creativity. New York, NY: Oxford University Press.

Simonton, D. K. (2003). Scientific creativity as constrained stochastic behavior: The integration of product, process, and person perspectives. Psychological Bulletin, 129, 475-494. doi:10.1037/0033-2909.129.4 .475

Simonton, D. K. (2007). The creative imagination in Picasso's Guernica sketches: Monotonic improvements or nonmonotonic variants? Creativity Research Journal, 19, 329-344. doi:10.1080/10400410701753291

Simonton, D. K. (2008). Willing creation. In J. Baer, J. C. Kaufman, \& R. F. Baumeister (Eds.), Are we free? Psychology and free will (pp. 296-303). New York, NY: Oxford University Press. doi:10.1093/ acprof:oso/9780195189636.003.0015

Simonton, D. K. (2010). Creativity as blind-variation and selectiveretention: Combinatorial models of exceptional creativity. Physics of Life Reviews, 7, 156-179. doi:10.1016/j.plrev.2010.02.002

Simonton, D. K. (2011a). Creativity and discovery as blind variation and selective retention: Multiple-variant definitions and blind-sighted integration. Psychology of Aesthetics, Creativity, and the Arts, 5, 222-228. doi:10.1037/a0023144

Simonton, D. K. (2011b). Creativity and discovery as blind variation: Campbell's (1960). BVSR model after the half-century mark. Review of General Psychology, 15, 158-174. doi:10.1037/a0022912

Simonton, D. K. (2011c). Debating the BVSR theory of creativity: Comments on Dasgupta (2011) and Gabora (2011). Creativity Research Journal, 23, 381-387. doi:10.1080/10400419.2011.621861

Simonton, D. K. (2012a). Combinatorial creativity and sightedness: Monte Carlo simulations using three-criterion definitions. The International Journal of Creativity \& Problem Solving, 22, 5-17.

Simonton, D. K. (2012b). Creativity, problem solving, and solution set sightedness: Radically reformulating BVSR. The Journal of Creative Behavior, 46, 48-65. doi:10.1002/jocb.004

Simonton, D. K. (2012c). Taking the US Patent Office creativity criteria seriously: A quantitative three-criterion definition and its implications. Creativity Research Journal, 24, 97-106.

Simonton, D. K. (2013a). Creative problem solving as sequential BVSR: Exploration (total ignorance) versus elimination (informed guess). Thinking Skills and Creativity, 8, 1-10. doi:10.1016/j.tsc.2012.12.001

Simonton, D. K. (2013b). Creative thought as blind variation and selective retention: Why sightedness is inversely related to creativity. Journal of Theoretical and Philosophical Psychology. doi:10.1037/a0030705

Simonton, D. K. (2013c). What is a creative idea? Little-c versus Big-C creativity. In J. Chan \& K. Thomas (Eds.), Handbook of research on creativity. Cheltenham Glos, UK: Edward Elgar. 
Simonton, D. K., \& Damian, R. I. (2013). Creativity. In D. Reisberg (Ed.), Oxford handbook of cognitive psychology (pp. 795-807). New York, NY: Oxford University Press.

Sober, E. (1992). Models of cultural evolution. In P. Griffiths (Ed.), Trees of life: Essays in philosophy of biology (pp. 17-39). Cambridge, MA: MIT Press.

Stavridou, A., \& Furnham, A. (1996). The relationship between psychoticism, trait-creativity and the attentional mechanism of cognitive inhibition. Personality and Individual Differences, 21, 143-153. doi:10.1016/ 0191-8869(96)00030-X

Sternberg, R. J. (1998). Cognitive mechanisms in human creativity: Is variation blind or sighted? The Journal of Creative Behavior, 32, 159176. doi:10.1002/j.2162-6057.1998.tb00813.x

Thagard, P. (2012). Creative combination of representations: Scientific discovery and technological invention. In R. Proctor \& E. J. Capaldi (Eds.), Psychology of science: Implicit and explicit processes. New York, NY: Oxford University Press. doi:10.1093/acprof:oso/ 9780199753628.003 .0016
Thagard, P., \& Stewart, T. C. (2011). The AHA! experience: Creativity through emergent binding in neural networks. Cognitive Science: A Multidisciplinary Journal, 35, 1-33.

Toulmin, S. (1972). Human understanding: The collective use and evolution of concepts. Princeton, NJ: Princeton University Press.

Vohs, K., Redden, J., \& Rahinel, R. (in press). Physical order produces healthy choices, generosity, conventionality, whereas disorder produces creativity. Psychological Science.

Wan, W. W. N., \& Chiu, C.-Y. (2002). Effects of novel conceptual combination on creativity. The Journal of Creative Behavior, 36, $227-$ 240. doi:10.1002/j.2162-6057.2002.tb01066.x

Received January 8, 2013

Revision received March 13, 2013

Accepted April 1, 2013 